\title{
Functional characterization of the domains of the bovine binder of SPerm 5 (BSP5) protein
}

\author{
Prashanth Sirigeri Jois ${ }^{1 \dagger}$, Geneviève Plante ${ }^{1,2 \dagger}$, Isabelle Thérien ${ }^{1}$ and Puttaswamy Manjunath ${ }^{1,2,34^{*}}$
}

\begin{abstract}
Background: Bovine BSP5 is a multifunctional protein primarily involved in sperm capacitation. BSP5 consists of long N-terminal part followed by two similar and highly conserved fibronectin type II domains designated A and B.

Methods: In order to assess the role of these domains in the sperm binding and capacitation processes, we created recombinant individual domains ( $N, A, B$ ), series of overlapping domains (NA and $A B$ ) and full-length BSP5 in an Escherichia coli expression system. The recombinant constructs were also tested for their ability to interact with ligands such as gelatine, heparin, chondroitin sulphate B and phosphatidylcholine liposomes by affinity chromatography and co-sedimentation studies.

Results: With the exception of the $\mathrm{N}$ domain, all recombinant constructs retained gelatine, phosphatidylcholine, heparin and chondroitin sulphate B binding activities. Domain-wise studies showed clearly that AB domain is capable of performing its biological functions as well as the full-length protein, as it was able to potentiate heparin-mediated sperm capacitation.

Conclusions: These results indicate that the C-terminal domain composed of two Fn2 domains is sufficient and crucial to maintain the biological functions of BSP proteins. The N-terminal part of the protein did not bind to any of known BSP5-ligands including epididymal sperm and did not seem to be required for either sperm binding or sperm capacitation. This study also confirmed that glycosylation is not required for BSP-mediated sperm capacitation or any of the binding characteristics displayed by BSP5.
\end{abstract}

Keywords: BSP5, Fibronectin type II domain, Escherichia coli expression system, Recombinant domains, Bovine sperm, Capacitation

\section{Background}

Seminal plasma is a complex mixture of secretions from testes, epididymides and accessory sex glands. Several components of mammalian seminal plasma are involved in the membrane remodeling processes occurring during sperm maturation [1]. Among these, proteins of Binder of SPerm (BSP) superfamily, previously called Bovine Seminal Plasma proteins, are the most studied in terms of biochemical properties, structure and functions [2].

The BSP proteins all have a common structure composed of a variable $\mathrm{N}$-terminal part followed by two tandem fibronectin type-II (Fn2) domains characterized by

\footnotetext{
*Correspondence: puttaswamy.manjunath@umontreal.ca

${ }^{\dagger}$ Equal contributors

${ }^{1}$ Maisonneuve-Rosemont Hospital Research Centre, Montreal, QC, Canada ${ }^{2}$ Department of Biochemistry and Molecular Medicine, Faculty of Medicine, University of Montreal, Quebec, Canada

Full list of author information is available at the end of the article
}

the presence of several highly-conserved aromatic residues and four invariant cysteine residues forming intradomain disulfide bonds with the connectivities $1-3$ and $2-4$. Initially discovered in the bovine seminal plasma, BSP protein homologs have since then been purified and characterized from seminal plasma of boar, goat, ram, bison, buffalo and stallion [3-9]. BSP homologous DNA sequences have also been identified in the genomes of human, mouse, rat, dog and chimpanzee; and BSP-like epididymal proteins have been identified in rabbit, human and mouse [10-14].

In bovine species, three proteins BSP1, BSP3 and BSP5 (previously called PDC-109 or BSP-A1/A2, BSP-A3 and BSP-30 kDa respectively) have been purified and biochemically characterized $[15,16]$. The three proteins are glycosylated to various extents, BSP5 being the most glycosylated and BSP3 having no glycosylation at all. They 
are known to bind to sperm upon ejaculation via an interaction with choline phospholipids. Interestingly, as opposed to BSP1 and BSP3, which binds specifically to choline phospholipids, BSP5 has been shown to display a broader binding specificity to lipids [17]. Some studies performed with BSP1 demonstrated that its binding to phosphatidylcholine (PC) liposomes and to bovine epididymal sperm membrane is a very rapid, biphasic process [18]. In the first step, the BSP protein recognizes and interacts with the choline head group of the phospholipid. This causes a conformational change in the protein, which enables the penetration of short segments of the protein in the hydrophobic interior of the membrane up to the fourteenth atom of carbon of the phospholipid [19-21]. When BSP proteins are in low concentrations, this interaction ultimately results in the rigidification of the lipid phase $[18,22]$.

Through this interaction with phospholipids, BSP proteins also play dual roles in bovine sperm capacitation, a complex series of molecular modifications that mammalian sperm must undergo before fertilizing an oocyte. Via membrane stabilization, BSP proteins act as decapacitating factors. They protect sperm during their transit through the female genital tract following ejaculation and prevent premature sperm capacitation. Bovine BSP proteins also promote sperm capacitation by inducing cholesterol and phospholipid efflux from sperm [23, 24]. They can induce this efflux when they are found in high concentrations or through interactions with high-density lipoproteins and glycosaminoglycans (GAGs) such as heparan sulphate found in follicular fluid [25, 26].

BSP proteins in bovine species bind to diverse ligands such as gelatine [15], heparin [27], other GAGs [28] and apolipoprotein A-I [29]. They also bind to components of semen extenders namely, egg yolk-low density lipoproteins and major milk proteins (caseins, $\alpha$-lactalbumin and $\beta$-lactoglobulin) used for semen preservation. This interaction is important for sperm protection [30] [31]. The mechanisms to regulate and coordinate the interaction of BSP proteins with diverse set of ligands in order to accomplish function(s) are not clear. In addition to their role in sperm capacitation, other functions have been proposed for bovine BSPs such as the mediation of sperm binding to the oviductal epithelium, the formation of the sperm reservoir and the ability to prolong sperm survival and motility in the oviduct [32, 33]. Recent studies also reported that bovine BSP1 can function as a molecular chaperone in vitro [34].

So far, most of the knowledge on BSP proteins has been obtained from the study of bovine BSP1, as this protein is found in the highest concentration in bovine seminal plasma [35]. However, BSP5 is known to have the longest N-terminal domain, to be the most glycosylated and to be the most active member of the bovine
BSP proteins $[26,25]$. Very few studies have been done to understand if the individual domains in multi-domain proteins such as BSP5 have ligand binding specificity and exercise biological function(s). The importance of the glycosylation in BSP function(s) and the minimal functional unit required to mediate the sperm capacitation are also not known.

In the current study we successfully cloned, expressed and purified domains (N, A and B), linear combination of domains (NA and $\mathrm{AB}$ ) and the full length BSP5 employing Escherichia coli as host. We then analyzed the ligand binding properties and the biological activities of individual and overlapping recombinant domains of bovine BSP5.

\section{Methods}

Plasmids pET32a(+) and pET30(+), Escherichia coli strains BL21(DE3)pLysS and Origami B(DE3) and His-bind resin were from Novagen (EMD Biosciences, La Jolla, CA, USA). Pfu DNA polymerase was from Fermentas (Burlington, ON, Canada) and Taq DNA polymerase was from GE Healthcare (Baie d'Urfe, QC, Canada). Restriction enzymes BamHI and XhoI were from New England Biolabs (Beverly, MA, USA). QIAprep Spin Miniprep kit and Qiaex II gel extraction kit were from Qiagen (Mississauga, ON, Canada). T4 DNA ligase was from Invitrogen (Carlsbad, CA, USA). For Western blotting, the His-probe monoclonal antibody (H-3) was from Santa Cruz Biotechnology (Santa Cruz, CA, USA), whereas goat anti-mouse IgG and goat antirabbit IgG were from Bio-Rad (Mississauga, ON, Canada). Chemiluminescence reagent was from PerkinElmer (Boston, MA, USA). Complete Mini, EDTA-free protease inhibitor tablets were from Roche (Manheim, Germany). B-PER bacterial extraction reagent was from Pierce (Rockford, IL, USA). Bovine serum albumin (BSA; fraction $\mathrm{V}$ fatty acid-free), heparin (purified from porcine intestinal mucosa), taurine, L-epinephrine, erythrosin B, flavianic acid (naphthol), lyso-phosphatidylcholine (lysoPC; purified from egg yolk) were from Sigma-Aldrich Canada (Oakville, ON, Canada). Penicillin G and streptomycin sulphate were from Gibco (Burlington, ON, Canada), eosin B from Fisher Scientific (Ottawa, ON, Canada) and nigrosin from Kodak (Rochester, NY, USA). All other chemicals used were of analytical grade and obtained from commercial suppliers.

\section{Construction of BSP5 expression vectors}

To generate expression vectors for the production of full-length bovine BSP5 (FL; residues 1-158), individual domains (N, A and $\mathrm{B}$ ) and linear combination of domains (NA and $\mathrm{AB}$ ), corresponding regions of the BSP5 gene were amplified by polymerase chain reaction using bovine seminal vesicle cDNA as template. The amplified 
DNA of the $\mathrm{N}$ domain was inserted into a pET30a vector and expressed in E. coli BL21(DE3) cells as described previously [36]. All the other domains were cloned in pET32a vectors and were expressed in E. coli Origami $\mathrm{B}(\mathrm{DE} 3)$ cells. As control, the empty pET32a vector was transformed in E. coli BL21(DE3) cells to express the thioredoxin-His-S tag (Trx-His-S).

\section{Expression and purification}

Bacteria were grown at $37^{\circ} \mathrm{C}$ in Luria-Bertani medium containing either ampicillin $(100 \mu \mathrm{g} / \mathrm{ml})$ or kanamycin $(50 \mu \mathrm{g} / \mathrm{ml})$ until $\mathrm{OD}_{600 \mathrm{~nm}}$ reached $\sim 0.8$. Induction was then carried out with $100 \mu \mathrm{M}$ isopropyl- $\beta$-d-galactopyranoside (IPTG) at $15{ }^{\circ} \mathrm{C}$ for $16 \mathrm{~h}$. For the $\mathrm{FL}$ protein, the individual domains (A and $\mathrm{B}$ ), the linear combination of domains (NA and $\mathrm{AB}$ ) and the Trx-His-S control, harvested cells were lysed by sonication in $50 \mathrm{mM}$ Tris$\mathrm{HCl}$ ( $\mathrm{pH}$ 7.9), $150 \mathrm{mM} \mathrm{NaCl}, 40 \mathrm{mM}$ imidazole buffer, containing $10 \%$ B-PER (v/v), and protease inhibitor cocktail. They were then purified by Ni-NTA affinity chromatography according to the manufacturer's instructions. Proteins were eluted from the column using buffer containing $250 \mathrm{mM}$ imidazole.

As the N-terminal part was sensitive to protease, boiling lysis instead of sonication was used to purify the protein as previously described [36]. Briefly, the cell suspension was incubated in boiling water for $20 \mathrm{~min}$, cooled on ice for $5 \mathrm{~min}$, and centrifuged at $4{ }^{\circ} \mathrm{C}$, at 15 $000 \mathrm{rpm}$ for $1 \mathrm{~h}$. The supernatant was purified by NiNTA affinity chromatography similar to the other constructs. The purity of each construct was examined by SDS-PAGE. Five micrograms of each sample were separated on a $15 \%$ polyacrylamide gel followed by Coomassie Brilliant Blue staining. Fractions containing purified protein were pooled, dialysed against $50 \mathrm{mM}$ ammonium bicarbonate and lyophilized.

The native BSP5 protein used as control in the experiments was purified from bovine seminal plasma by gelatine-agarose affinity chromatography as previously described [15]. The protein estimations were done by a modified Lowry method [37]. Lyophilized protein samples were weighed in the microbalance (Cahn C-31) and appropriate quantities were used for the subsequent studies.

\section{Affinity chromatography}

All the binding studies by affinity chromatography were performed at $4{ }^{\circ} \mathrm{C}$ at a flow rate of $20 \mathrm{ml} / \mathrm{h}$. For the binding to gelatine, five hundred micrograms of the lyophilized recombinant constructs and Trx-His-S were solubilised in $5 \mathrm{ml}$ of TB (Tris-Buffer; $50 \mathrm{mM}$ Tris- $\mathrm{HCl}$, $\mathrm{pH}$ 7.4) and centrifuged $10000 \times g$ for $10 \mathrm{~min}$ to remove any insoluble material. The supernatant were then applied on a gelatine-agarose column (bed volume of $2 \mathrm{ml}$ ) previously equilibrated with TB. The column was washed with 10 bed volumes of TB and adsorbed proteins were eluted with TB containing $8 \mathrm{M}$ urea.

For the binding to glycosaminoglycans, $1 \mathrm{mg}$ of recombinant BSP5 protein constructs in $1 \mathrm{ml}$ of the TB containing $40 \mathrm{mM} \mathrm{NaCl}$ was applied to a heparin-sepharose or a chondroitin sulphate B-agarose column (bed volume, $1 \mathrm{ml}$ ) equilibrated in TB containing $40 \mathrm{mM} \mathrm{NaCl}$. The columns were washed with 10 bed volumes of the same buffer and the adsorbed material was eluted with TB containing $1 \mathrm{M} \mathrm{NaCl}$ and with the $\mathrm{TB}$ containing $8 \mathrm{M}$ urea. For all the chromatography assays, fractions of $1 \mathrm{ml}$ were collected and protein elution was monitored by optical density measured at $280 \mathrm{~nm}$. Proteins from each peak were pooled, concentrated by ultrafiltration, precipitated with $15 \%$ trichloroacetic acid (TCA) and analyzed by $15 \%$ SDS-PAGE followed by staining with Coomassie Brilliant Blue.

\section{Lipid vesicle co-sedimentation assay}

Liposomes of phosphatidylcholine (PC) were prepared as described in [17]. Briefly, $8 \mathrm{mg}$ of PC (Doosan Sedary Research Laboratories; Englewood Cliffs, NJ, USA) in chloroform was evaporated under $\mathrm{N}_{2}$ until a thin film was formed in the bottom of a glass tube. PC was then resuspended in $2 \mathrm{ml}$ buffer $(10 \mathrm{mM}$ Tris- $\mathrm{HCl}, 100 \mathrm{mM}$ $\mathrm{KCl}, \mathrm{pH} 7.5)$ and the tube was sonicated in a Branson Ultrasonic water bath (Model 3510) for $\sim 1 \mathrm{~min}$ at RT until lipids formed an opalescent suspension. Large multi-lamellar liposomes were sedimented by ultracentrifugation at $100000 \times g$ at $25^{\circ} \mathrm{C}$ for $30 \mathrm{~min}$. The pellet containing liposomes was resuspended in buffer $\mathrm{B}$ (10 mM Tris- $\mathrm{HCl}, 100 \mathrm{mM} \mathrm{KCl}, 2.5 \mathrm{mM} \mathrm{MgCl}_{2}$, $\mathrm{pH}$ 7.5), to obtain a final lipid concentration of $4 \mathrm{mg} / \mathrm{ml}$. To test the binding to PC liposomes, $20 \mu \mathrm{g}$ of recombinant BSP5 constructs, $10 \mu \mathrm{g}$ of Trx-His-S and $10 \mu \mathrm{g}$ of BSP5 were incubated with liposomes (equivalent to $150 \mu \mathrm{g}$ PC), in a total volume of $300 \mu \mathrm{l}$ of buffer B. Incubations were carried out for $30 \mathrm{~min}$ at RT, after which liposomes were centrifuged once again at $100000 \times g$ at $25{ }^{\circ} \mathrm{C}$ for $45 \mathrm{~min}$. Equivalent fractions of supernatant (proteins precipitated with $15 \% \mathrm{TCA}$ ) and pellet were analyzed by $15 \%$ SDS-PAGE followed by Coomassie Brilliant Blue staining and by Western blot.

\section{Sperm binding assay}

Bovine epididymides were obtained from a local slaughterhouse near Montreal. Cauda sperm collected from the epididymides were washed twice $(300 \times g, 10 \mathrm{~min})$ with 10 volumes of a modified Tyrode's medium designated mTALP $(100 \mathrm{mM} \mathrm{NaCl}, 2.7 \mathrm{mM} \mathrm{KC1}, 1.8 \mathrm{mM}$ $\mathrm{CaCl}_{2}, 0.5 \mathrm{mM} \mathrm{MgCl} 2,0.3 \mathrm{mM} \mathrm{NaH} \mathrm{PO}_{4}, 35.7 \mathrm{mM}$ $\mathrm{NaHCO}_{3}, 0.1 \mathrm{mM}$ sodium pyruvate, $17.4 \mathrm{mM}$ sodium lactate, $0.5 \mathrm{mM}$ taurine, $0.05 \mathrm{mM}$ L-epinephrine, $63 \mu \mathrm{g} / \mathrm{ml}$ penicillin $\mathrm{G}(1585 \mathrm{U} / \mathrm{mg}), 0.1 \mathrm{mM}$ streptomycin sulfate, 
and $20 \mu \mathrm{g} / \mathrm{ml}$ phenol red dye) [26]. Washed sperm $(10 \times$ $10^{6}$ cells) were then incubated in $1 \mathrm{ml}$ mTALP for $90 \mathrm{~min}$ at $39{ }^{\circ} \mathrm{C}$ with $20 \mu \mathrm{g} / \mathrm{ml}$ of respective recombinant BSP5 construct, $20 \mu \mathrm{g} / \mathrm{ml}$ Trx-His-S or $20 \mu \mathrm{g} / \mathrm{ml}$ native BSP5. Following the incubation, sperm were pelleted at $5000 \times g$ for $10 \mathrm{~min}$. The supernatant was removed and the pellet was washed three times with $1 \mathrm{ml}$ of PBS. The supernatant was precipitated with TCA (15\%, final concentration), resuspended in Laemmli sample buffer and boiled $10 \mathrm{~min}$. The pellet was resuspended in sample buffer, boiled $10 \mathrm{~min}$ and sonicated $1 \mathrm{~h}$ in a water bath. Supernatants and pellets were finally analyzed by western blot.

\section{Sperm capacitation and acrosome reaction}

Epididymal sperm were prepared as described above. Washed sperm (final concentration of $5 \times 10^{7} \mathrm{cells} / \mathrm{ml}$ ) were preincubated $\left(5 \% \mathrm{CO}_{2}, 39{ }^{\circ} \mathrm{C}\right)$ for $20 \mathrm{~min}$ in the presence or absence of different concentrations of each domain constructs. Sixty $\mu \mathrm{g} / \mathrm{ml}$ Trx-His-S and $30 \mu \mathrm{g} / \mathrm{ml}$ native BSP5 were used as negative and positive control respectively. The cells were then washed twice $(300 \times g$, $10 \mathrm{~min}$ ) and resuspended (final concentration of $5 \times 10^{7}$ cells $/ \mathrm{ml}$ ) with $12 \mu \mathrm{g} / \mathrm{ml}$ of heparin. After the $5 \mathrm{~h}$ incubation, two aliquots of each sample were taken. The first aliquots were re-incubated for $15 \mathrm{~min}$ in the absence (spontaneous acrosome reaction) or in the presence of $100 \mu \mathrm{g} / \mathrm{ml}$ of lyso-PC. This concentration of lyso-PC was previously shown to induce the acrosome reaction in capacitated sperm while having no effect on noncapacitated sperm [38]. The other sperm aliquots were used for immunofluorescence study.

\section{Staining procedure}

To assess acrosome reacted status of the bovine sperm, the naphthol yellow S-erythrosin B staining by Lenz et al. was used [39]. Briefly, the slides were placed in $0.1 \%$ naphthol yellow $\mathrm{S}$ in $1 \%$ aqueous acetic acid for $30 \mathrm{~min}$ and rinsed in $1 \%$ aqueous acetic acid for $10 \mathrm{~s}$. The slides were then drained, placed in a solution of $0.2 \%$ aqueous erythrosin $\mathrm{B}$ and $0.2 \%$ naphthol yellow $\mathrm{S}(\mathrm{pH} 4.8)$ for $13 \mathrm{~min}$, rinsed in distilled water, and air dried.

\section{Sperm viability}

Sperm viability was estimated by the staining protocol of Dott and Foster [40]. Briefly, an aliquot of each sperm suspension $(10 \mu \mathrm{l})$ was mixed with $5 \mu \mathrm{l}$ of eosin B $5 \%$, and $5 \mu \mathrm{l}$ of a saturated solution of nigrosin was added. The stained sperm were spread on glass slides, dried. Viable (white) and non-viable (red) sperm were counted under light microscopy in duplicate.

\section{Immunofluorescence microscopy}

Following capacitation in the presence of heparin, sperm incubated with $60 \mu \mathrm{g} / \mathrm{ml}$ of respective recombinant
BSP5 construct, $60 \mu \mathrm{g} / \mathrm{ml}$ Trx-His-S or $30 \mu \mathrm{g} / \mathrm{ml}$ native BSP5 were used for immunofluorescence. Aliquot of the sperm suspension $(10 \mu \mathrm{l})$ were mixed with $40 \mu \mathrm{l}$ of PBS and $50 \mu \mathrm{l}$ of $4 \%$ paraformaldehyde to fix the sperm for $30 \mathrm{~min}$ at RT after which $450 \mu \mathrm{l}$ of PBS were added. The sperm were pelleted at $2000 \times g$ for $10 \mathrm{~min}$, washed with $500 \mu \mathrm{l}$ of PBS and resuspended in a final volume of $20 \mu \mathrm{l}$ of PBS. Two aliquots of $5 \mu \mathrm{l}$ of the sperm suspension was applied to Poly-L-lysine slides and allowed to dry on a slide warmer. Sperm were permeabilized for 5 min with PBS containing $0.1 \%$ Triton-X-100 and $0.2 \%$ paraformaldehyde, and then washed 3 times with PBS. Nonspecific binding sites were blocked by incubating slides for $1 \mathrm{~h}$ at RT in PBS containing $1 \%$ of BSA. Slides were allowed to dry and then incubated $1 \mathrm{~h}$ at RT with anti-BSP5 polyclonal antibodies or with His-probe mouse antibodies (1:100) [16].

Slides were washed 3 times with PBS for $5 \mathrm{~min}$. Slides were allowed to dry and incubated at RT in a dark chamber for $1 \mathrm{~h}$ with the secondary FITC-labelled goat anti-rabbit IgG or secondary FITC-labelled goat antimouse IgG (1:200) in PBS-0.1 \% BSA. Slides were washed 3 times for $5 \mathrm{~min}$ in PBS and allowed to dry. Finally, a drop of $1.5 \%$ DABCO (10 ml of 1,4-diazabicyclo[2.2.2] octane $15 \%$ and $90 \mathrm{ml}$ of glycerol) was deposited on the slides. As controls for the specificity of the immunofluorescence, sperm without any added proteins were fixed and incubated with pre-immune sera and FITC-labelled secondary antibodies or with FITClabelled secondary antibodies alone. Fluorescence was visualized with a Leica DMRE microscope, and the data were acquired using a RETIGA EX digital camera (QIMAGING) coupled with OpenLab 3.1.1 software (OpenLab).

\section{Statistical analysis}

The data were analyzed for significant differences by one-way covariance analysis followed by LSD multiple comparison tests or by a Student $t$-test on paired observations using GraphPad Prism 5 software (GraphPad, San Diego, CA, USA).

\section{Results}

Expression and purification of recombinant constructs BSP5 is a 158 amino acid-protein composed of a highly glycosylated N-terminal part and two Fn2 domains separated by a 7 residues-linker (Fig. 1a). In the current study, six different recombinant constructs were cloned and expressed in order to analyze the ligand binding properties and the biological activities of individual and overlapping recombinant domains of bovine BSP5 (Fig. 1b). Cloning, expression and purification of the Nterminal domain has already been described previously [36]. Since this domain does not contain any disulphide 
A

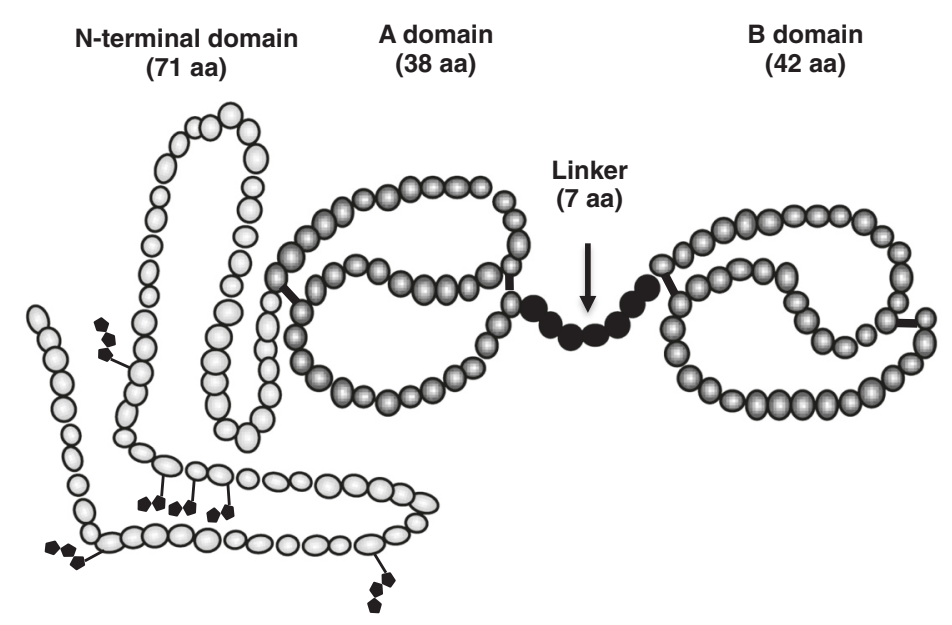

B

Constructs

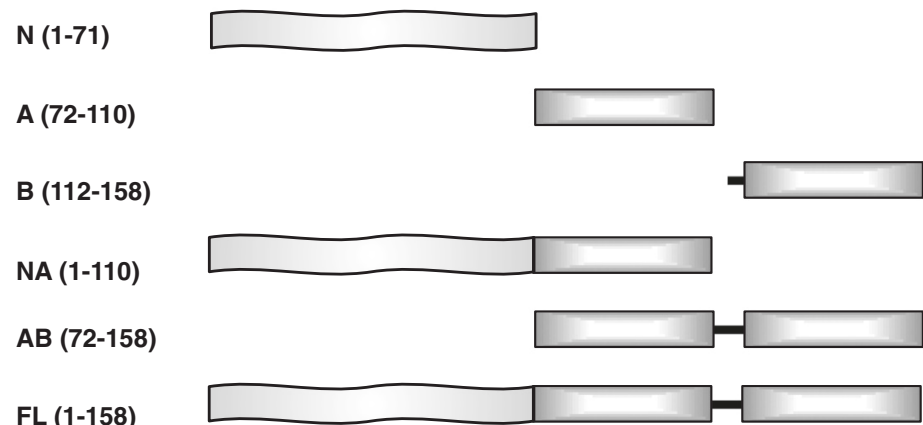

C

\section{Thioredoxin (Trx)}

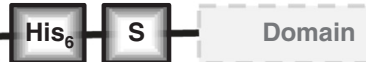

Fig. 1 Schematic representation of bovine BSP5 and the recombinant constructs. a Native full-length bovine BSP5 is a 158 amino acid-protein composed of an N-terminal part and two Fn2 domains ( $\mathbf{a}$ and $\mathbf{b})$ joined by a short linker. BSP5 is glycosylated on six residues of its $\mathrm{N}$-terminal domain. $\mathbf{b}$ Recombinant constructs of the BSP5 proteins used in this study. $\mathbf{c}$ The tag encoded by the pET32a(+) expression vector consists of a thioredoxin, followed by a (His) 6 -tag and a S-tag

bonds in its structure, it was cloned in a pET30a vector and is fused only to a (His) ${ }_{6}$-tag. To help with the formation of the Fn2 domains and with protein refolding, the other five constructs were expressed in pET32a expression vectors and were therefore fused with a larger tag composed of a thioredoxin tag, a $(\mathrm{His})_{6}$-tag and a Stag (Fig. 1c).

Trx-His-S tagged domains were expressed in E. coli BL21(DE3) cells and purified by $\mathrm{Ni}^{2+}$-NTA affinity chromatography. All purified domains were then analyzed by SDS-PAGE on $15 \%$ polyacrylamide gels stained with Coomassie Brilliant Blue. Constructs were more than $90 \%$ pure (Fig. 2). The two controls, Trx-His-S and native BSP5, were shown to have similar levels of purity.
Recombinant constructs N, A, B, NA, AB and FL were found to have apparent molecular weights of approximately 24, 29, 29, 32, 39 and $42 \mathrm{kDa}$ respectively as previously reported. Identity of the constructs was also confirmed by Western blot using anti-BSP5 polyclonal antibodies or His-probe monoclonal antibody (not shown).

\section{Binding properties}

Interaction of the recombinant constructs with gelatine, heparin and chondroitin sulfate B (CSB) was tested by affinity chromatography (Table 1 ). When less than five percent of the proteins were found in the adsorbed fraction, binding was considered as non-specific as was the case for the $\mathrm{N}$ domain as well as the negative control 


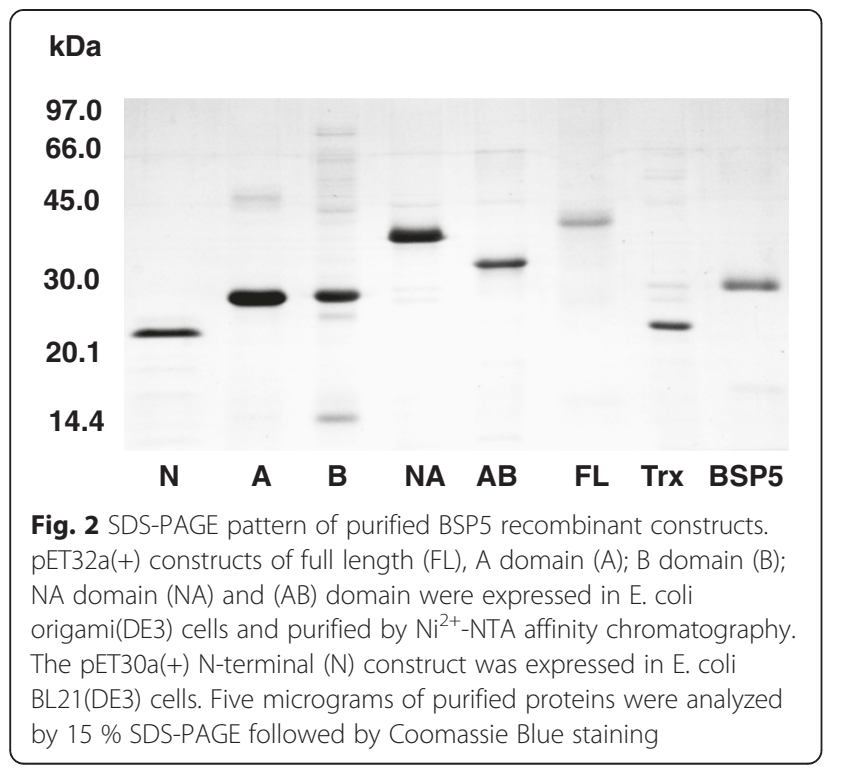

Trx-His-S. All the other constructs were found to interact with the ligands with varying affinities. As was previously observed for the native BSP5, the FL construct displayed a strong affinity for both gelatine and GAGs. Similar results were obtained with domains B and AB. In the case of domains A and NA, they showed strong affinity for heparin and CSB, but a slightly higher amount of proteins were found in the unabsorbed fraction.

Co-sedimentation was used to test the interaction of recombinant constructs with both PC liposomes and bovine epididymal sperm (Table 2). Binding was scored following SDS-PAGE and western blot when a band corresponding to the recombinant domain was visible in the pellet fraction containing the liposomes or epididymal sperm. Based on these criteria, similar results were obtained for binding to PC liposomes and to epididymal bovine sperm. All domains with the exception of $\mathrm{N}$ domain were found to interact with PC liposomes and epididymal sperm. Trx-His-S and $\mathrm{N}$-domain were only found in the supernatant fraction suggesting a lack of

Table 1 Summary of binding studies of recombinant BSP5 constructs by affinity chromatography

\begin{tabular}{llll}
\hline Constructs & Gelatine & Heparin & Chondroitin Sulfate B \\
\hline $\mathrm{N}$ & - & - & - \\
$\mathrm{A}$ & ++ & ++++ & +++ \\
$\mathrm{B}$ & +++ & +++ & +++ \\
$\mathrm{NA}$ & ++ & ++++ & +++ \\
$\mathrm{AB}$ & +++ & ++++ & +++ \\
$\mathrm{FL}$ & +++ & +++ & ++++ \\
Trx-His-S & - & - & -
\end{tabular}

$(-)<5 \%$ binding, (+) 5-25\%, (++) 26-50\%, (+++) 51-75\%, (++++) 76-100\%
Table 2 Summary of binding studies of recombinant BSP5 constructs to PC-liposomes and epididymal sperm by cosedimentation

\begin{tabular}{lll}
\hline Constructs & PC-liposomes & Epididymal sperm \\
\hline $\mathrm{N}$ & - & - \\
$\mathrm{A}$ & + & + \\
$\mathrm{B}$ & + & + \\
$\mathrm{NA}$ & + & + \\
$\mathrm{AB}$ & + & + \\
$\mathrm{FL}$ & + & + \\
Trx-His-S & - & - \\
\hline
\end{tabular}

(-) No binding, (+) Binding observed

interaction. As control, recombinant domains were also incubated in the absence of liposomes and centrifuged. Under those conditions, all domains were found in the supernatant fraction only (data not shown).

\section{Heparin-induced capacitation assay}

To examine whether the recombinant constructs of BSP5 were able to mediate heparin sperm capacitation, capacitation assays were carried out with different concentrations of the constructs, native BSP5 serving as positive control and Trx-His-S as negative control. Capacitation was assessed by the ability of sperm to undergo the AR induced by lyso-PC. Recombinant domains N, A, $B$ and NA did not cause any significant increase in the percentage of acrosome reaction observed following incubation of sperm in the presence of lyso-PC (Fig. 3a-d; white bars). Increasing concentrations of the recombinant $\mathrm{AB}$ and $\mathrm{FL}$ constructs however caused a significant dose-dependent increase in the percentage of sperm acrosome reaction induced by lyso-PC, with a protein concentration as low as $5 \mu \mathrm{g} / \mathrm{ml}$. Results obtained with $\mathrm{AB}$ and FL constructs were comparable to those to the native BSP5 positive control (Fig. 3e-f; white bars). Recombinant domains did not affect spontaneous acrosome reaction (without induction by lyso-PC), as after $5 \mathrm{~h}$ incubation with different domains, levels of acrosome reaction were equivalent to that of sperm incubated with media alone (Fig. 3; black bars).

\section{Sperm viability}

During the capacitation studies, the effect of recombinant proteins on sperm viability was also evaluated. None of the recombinant constructs including Trx-His-S affected the viability of the sperm (Fig. 4). At the beginning of the incubation with heparin approximately $75 \%$ of sperm were viable. A slight decrease was observed toward the end of the incubation, but this effect was observed for all conditions tested. 

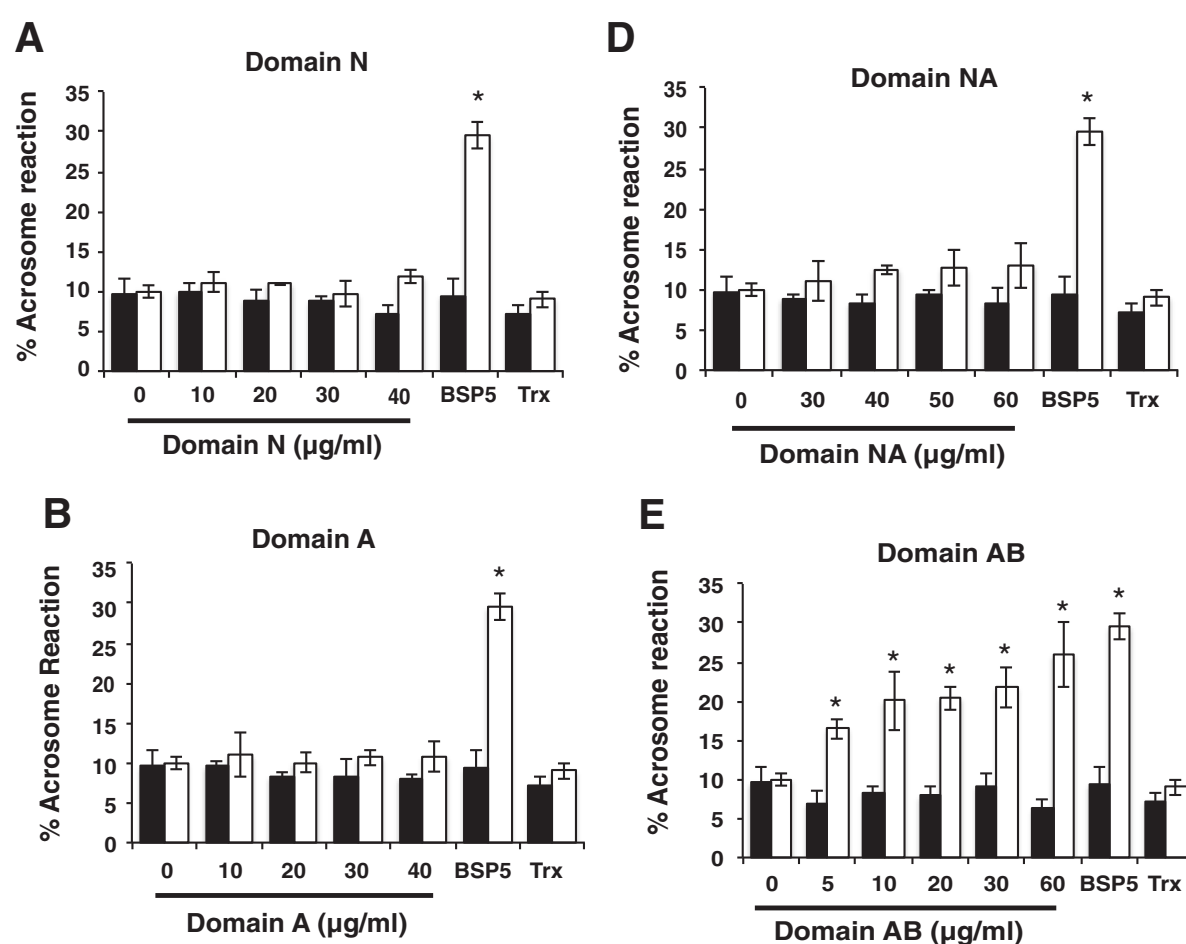

\section{$\mathbf{E}$}
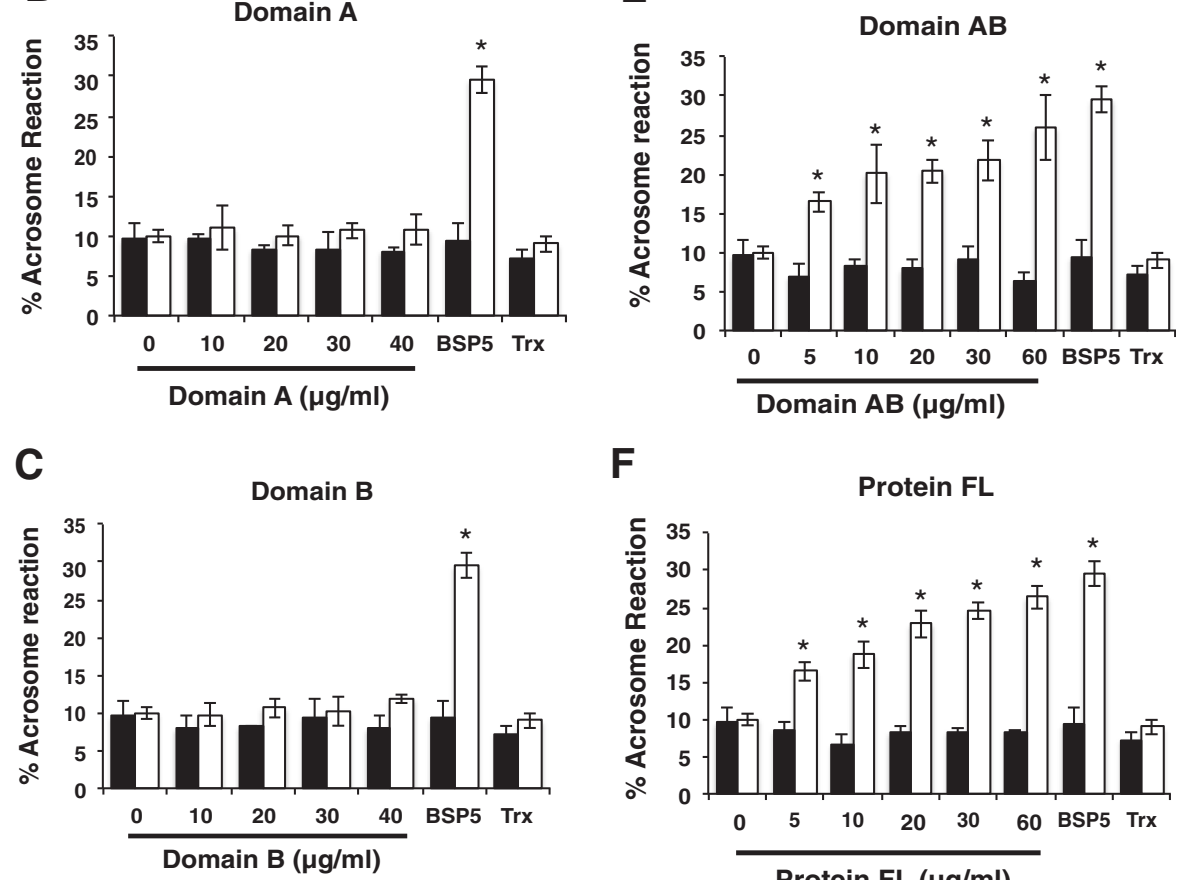

$\mathbf{F}$

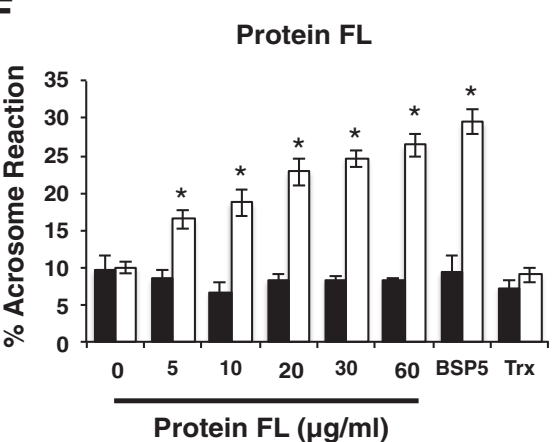

Fig. 3 Effect of recombinant BSP5 constructs on lyso-PC-induced acrosome reaction of epididymal sperm incubated with heparin. Sperm collected from cauda epididymis were incubated for $20 \mathrm{~min}$ alone or in media containing increasing concentrations of the different BSP5 constructs, $60 \mu \mathrm{g} / \mathrm{ml} \mathrm{Trx}$-His-S or $30 \mu \mathrm{g} / \mathrm{ml}$ native BSP5. Sperm were then washed, incubated with $12 \mu \mathrm{g} / \mathrm{ml}$ of heparin for $5 \mathrm{~h}$ and incubated an additional $15 \mathrm{~min}$ in presence (white bars) or absence (black bars) of $100 \mu \mathrm{g} / \mathrm{ml}$ lyso-PC. Acrosome reaction was assessed by naphtol yellow S-erythrosin B staining. Data are presented as the mean \pm SD of three independent experiments. Differences compared to control (no proteins added) were analyzed by one-way covariance analysis followed by LSD multiple comparison tests $\left({ }^{*} p<0.05\right)$. Panels (a-f) correspond respectively to Domain N, Domain A, Domain B, Domain NA, Domain AB and Protein FL (Full length)

\section{Immunolocalization of recombinant BSP5 constructs on bovine epididymal sperm}

Binding of constructs to epididymal sperm was also confirmed by immunolocalization studies as signals were observed on epididymal sperm for all recombinant constructs except the N-terminal domain. As reported previously, the positive control, native BSP5, bound to more than $95 \%$ of the epididymal sperm cells [41]. Recombinant constructs $\mathrm{AB}$ and $\mathrm{FL}$ were found at the surface of $~ 50 \%$ of the epididymal sperm. The other domains A, B and NA were also detected on sperm surface, but on fewer sperm
(Not shown). The intensity of the signal for domains A and $B$ was also weaker.

To determine if the recombinant constructs and native BSP5 protein remain bound to sperm after capacitation processes, aliquots of sperm were taken at the end of the capacitation prior to the incubation with lyso-PC and evaluated by immunofluorescence (Fig. 5). Patterns observed were similar to those observed in non-capacitated conditions indicating that proteins were still present, and that localization of the domains on sperm surface did not change following capacitation. The binding of 


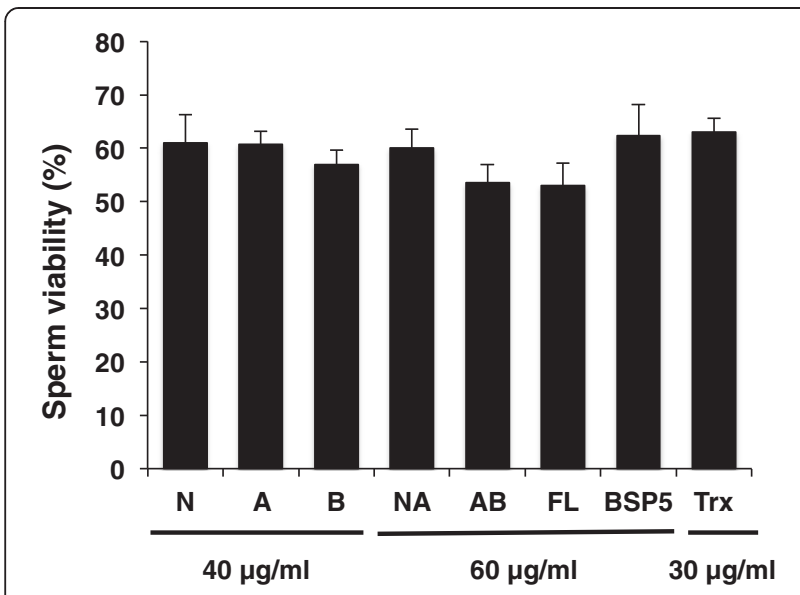

Fig. 4 Effect of recombinant BSP5 constructs on the viability of epididymal sperm incubated with heparin. Sperm collected from epididymis were incubated for $20 \mathrm{~min}$ alone or in media containing $40 \mu \mathrm{g} / \mathrm{ml}$ of constructs $\mathrm{N}, \mathrm{A}$ and $\mathrm{B}, 60 \mu \mathrm{g} / \mathrm{ml}$ of constructs $\mathrm{NA}, \mathrm{AB}$ and $\mathrm{FL}, 60 \mu \mathrm{g} / \mathrm{ml}$ Trx-His-S or $30 \mu \mathrm{g} / \mathrm{ml}$ native BSP5. Sperm were then washed, incubated with $12 \mu \mathrm{g} / \mathrm{ml}$ of heparin for $5 \mathrm{~h}$. Viability was assessed by staining with eosin/nigrosin solutions. Data are presented as the mean \pm SD of three independent experiments

the recombinant constructs $(\mathrm{A}, \mathrm{B}, \mathrm{NA}, \mathrm{AB}$ and $\mathrm{FL})$, like the binding of native BSP5, was not restricted to head portion of the sperm as proteins were also localized to the midpiece of the sperm. No signal was obtained when sperm were incubated without protein (control) or with Trx-His-S using His-probe antibody as primary antibody.

\section{Discussion}

Bovine BSP proteins are multifunctional proteins, via their interaction with cell membranes and with proteins such as GAGs. Heparan sulfate and other GAGs like heparin and chondroitin sulphate $B$ are present in oviductal and follicular fluids of bovine species [28]. Since heparin is commonly used to induce the sperm capacitation in bovine species [26], it was of interest to check if the recombinant BSP5 protein constructs could bind to heparin and chondroitin sulphate B. It is not surprising that the N-terminal part of the protein did not show any interaction with the GAGs, as this domain is rich in negatively charged amino acids and does not contain the known heparin binding-consensus sequences $\mathrm{B}-\mathrm{B}-\mathrm{X}-\mathrm{B}$ or $\mathrm{B}-\mathrm{X}-\mathrm{X}-\mathrm{B}-\mathrm{X}-\mathrm{B}-\mathrm{B}$ (where $\mathrm{B}$ represent basic residues and $\mathrm{X}$ represents any residues) [42, 27]. All the other recombinant constructs displayed expected binding characters with respect to heparin and chondroitin sulphate B. Results seem to suggest that glycosylation is not essential for the binding of bovine BSP proteins to heparin or chondroitin sulphate $\mathrm{B}$. These results contradict the observation reported for porcine and equine BSP proteins. In these species, it seems that glycosylation can modulate the aggregation state of the BSP proteins and thus has an indirect effect on the ability of these proteins to bind to heparin [43].

Although gelatine binding is a characteristic feature of Fn2 domains, the biological relevance of this property in bovine BSP proteins is not known. Of all the domains tested in the current study, only the N-terminal domain failed to interact with gelatine. Results obtained are in accordance with previous experiments performed with BSP1 B domain isolated by tryptic digestion [44]. Interestingly, results seem to suggest that B domain has a greater affinity than domain $\mathrm{A}$, even with the presence of the $\mathrm{N}$ terminal part in the NA construct. This slightly lower affinity of A and NA constructs could possibly be due to the presence of a phenylalanine residue in position 108 of the BSP5 protein sequence. Indeed some previous studies on the structure of Fn2 domains have shown that a tyrosine residue in this position is necessary for strong gelatine binding [45].

As expected, A, B, NA, AB and FL constructs, which contain one or two Fn2 domains, interacted with PC liposomes. This is in agreement with the established fact that the Fn2 domains are responsible for the binding to PC groups [46, 20]. The PC ligand binding is mediated by a cation- $\pi$ interaction between the quaternary ammonium group of the choline moiety and the indole ring of a core tryptophan residue, and hydrogen bonding between the phosphate group and exposed tyrosine residues of the BSP proteins [20]. In contrast, the negatively charged N-terminal part did not interact with neutral lipid PC. As BSP proteins bind to sperm via an interaction with choline phospholipids, all recombinant domains interacting with $\mathrm{PC}$ liposomes also bound to bovine epididymal sperm.

In this study, we also demonstrated for the first time that the native BSP5 protein and all recombinant constructs, except the $\mathrm{N}$ domain, remained associated with sperm even after heparin-mediated capacitation. These results are in contradiction with the work previously published by Hung et al., who observed a complete loss of BSP5 on sperm surface following 5 h-incubations in the presence and absence of heparin [47]. This discrepancy could be due to the different antibody used in each study. Hung et al., used an antibody against an $\mathrm{N}$ terminal peptide of the BSP5 protein, whereas the antibody used in the current study was prepared against the full-length native BSP5 protein. This difference between studies could suggest, that during sperm capacitation or during prolonged incubation, BSP5 is not lost, but is partly cleaved or modified at its $\mathrm{N}$-terminal part.

After binding studies, the recombinant domains were tested for their ability to induce heparin-mediated sperm capacitation. As mentioned previously, the acrosome reaction induced by lyso-PC in the present context is meant to reflect capacitation. Recombinant $\mathrm{AB}$ domain 

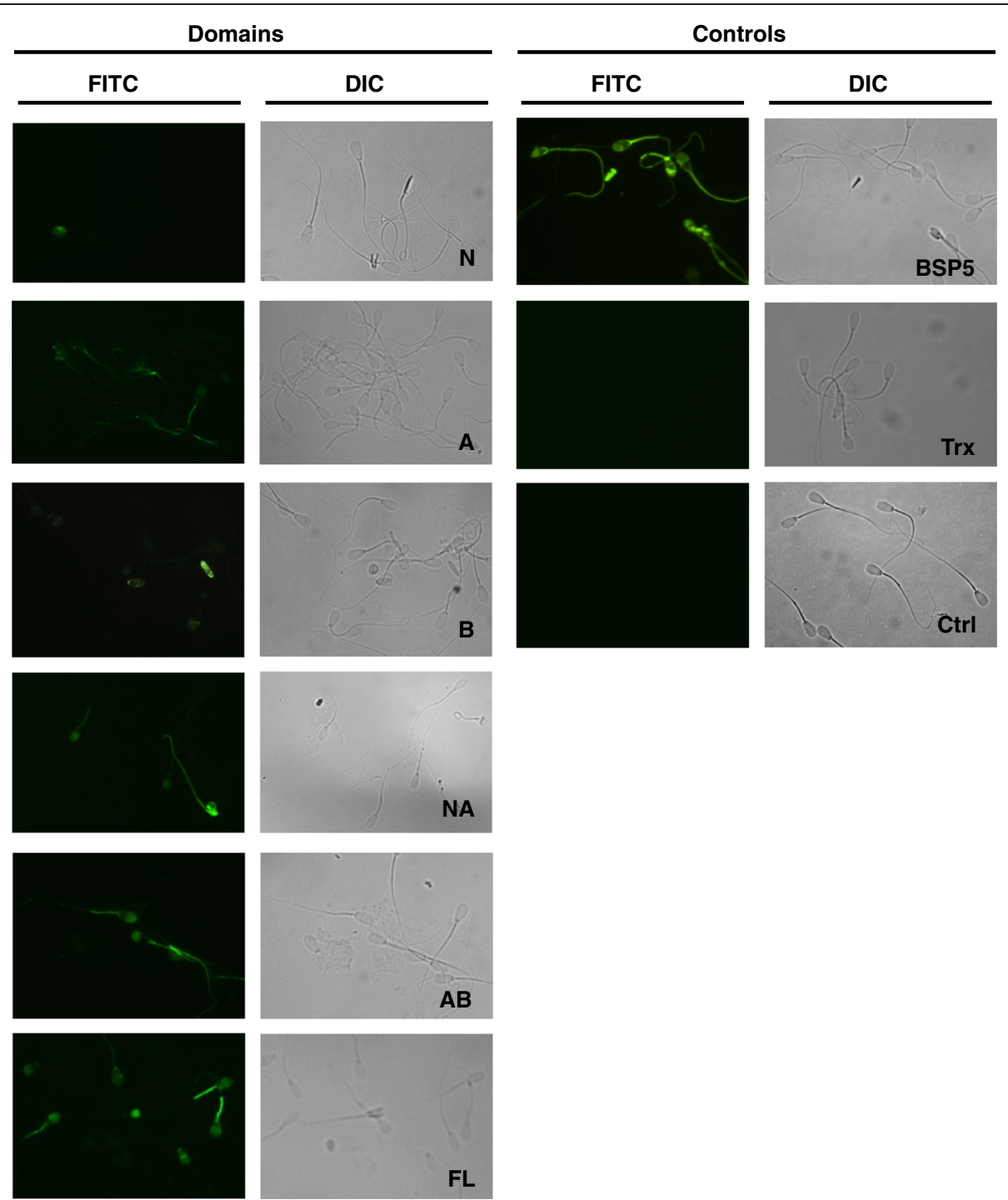

Fig. 5 Immunostaining of recombinant BSP5 constructs on heparin-capacitated sperm. Sperm from cauda epididymis were incubated 20 min alone (Ctrl) or in media containing $60 \mu \mathrm{g} / \mathrm{ml}$ of each construct, $60 \mu \mathrm{g} / \mathrm{ml}$ Trx-His-S or $30 \mu \mathrm{g} / \mathrm{ml}$ native BSP5. Sperm were then washed and incubated for $5 \mathrm{~h}$ with $12 \mu \mathrm{g} / \mathrm{ml}$ of heparin. Aliquots of the samples were dried on poly-L-lysine slides. Slides were then incubated with anti-BSP5 or His-probe (Trx-His-S slide) antibodies at dilution of 1:100 and treated with FITC-conjugated IgG. (Original magnification $\times 630$; DIC, Differential Interference Contrast)

and full-length BSP5 protein stimulate the capacitation to the level comparable to native BSP5 protein. The recombinant $\mathrm{A}, \mathrm{B}, \mathrm{NA}$ and $\mathrm{N}$ domains and the control Trx-His-S construct did not have any effect on the sperm capacitation mediated by heparin. These results are in agreement with results obtained by Moreau et al., showing that the B domain of BSP1 is not sufficient to stimulate sperm cholesterol efflux associated with capacitation [44]. Since there is no difference in stimulation in the level of sperm capacitation observed in presence of the $A B$ construct versus the full-length construct, it seems that the N-terminal part does not appear to play role in sperm capacitation. Similar functional mapping studies on the human ZP3, which acts as a primary sperm receptor, have concluded that the functional activity of the protein resides in its $\mathrm{C}$-terminal domain [48]. Similar functional mapping studies of sperm proteins have also been used to define parts of proteins, which could be used as contraceptive antigen [49].

As reported previously for experiments with the native BSP5 protein [26], the spontaneous acrosome reaction remained low in the presence of all recombinant constructs. This suggests that similar to the native BSP5 protein, the recombinant constructs cannot stimulate 
the acrosome reaction by themselves, and induction by lyso-PC is essential for stimulation of the acrosome reaction of capacitated sperm. All these results tend to demonstrate that the domains $\mathrm{A}$ and $\mathrm{B}$ together constitute the minimal functional unit for sperm capacitation induced by heparin. Since recombinant protein constructs were expressed in E. coli, it became evident that glycosylation is not required for BSP binding to sperm or for its function in heparin-induced capacitation. It is therefore possible that the glycosylation of BSP proteins is not required for them to perform their function, but could play other roles. For example, mouse sperm protein IZUMO, a protein essential for sperm fusion with eggs, glycosylation is not required for the function but has a protective role [50].

\section{Conclusions}

In conclusion, this study demonstrates that two tandem fibronectin domains at the C-terminus part of the protein are sufficient to mediate the sperm capacitation in bovine BSP5. The N-terminal part and glycosylation have no direct role in mediating sperm binding or capacitation or acrosome reaction. As the modular structure of BSP proteins is highly conserved among mammals, these results could be extended to other members of BSP superfamily. The function of $\mathrm{N}$-terminal part still remains elusive. BSP proteins were discovered three decades ago, some new functions have been proposed in the recent years for these proteins. It will be interesting, to know, if the N-terminal part of the BSP proteins and/ or its glycosylation is important for these new functions.

\section{Competing interests}

The authors declare that they have no competing interests.

\section{Authors' contributions}

PSJ cloned, expressed and purified the recombinant constructs. He also performed the binding part of the binding studies. GP purified some of the recombinant constructs and performed some of the binding studies. IT performed capacitation, viability and immunofluorescence experiments. All authors participated in the analysis of the results and the redaction of the manuscript. All authors read and approved the final manuscript.

\section{Acknowledgements}

This work was supported by the Canadian Institutes of Health Research (grant number MOP-130274).

\section{Author details \\ ${ }^{1}$ Maisonneuve-Rosemont Hospital Research Centre, Montreal, QC, Canada. ${ }^{2}$ Department of Biochemistry and Molecular Medicine, Faculty of Medicine, University of Montreal, Quebec, Canada. ${ }^{3}$ Department of Medicine, Faculty of Medicine, University of Montreal, Quebec, Canada. ${ }^{4}$ Maisonneuve-Rosemont Hospital Research Center, 5415 I'Assomption blvd, Montreal, QC H1T 2 M4, Canada.}

Received: 29 April 2015 Accepted: 2 June 2015

Published online: 19 June 2015

\footnotetext{
References

1. Shivaji S, Scheit KH, Bhargava PM. Proteins of seminal plasma. New York: Wiley; 1990.
}

2. Manjunath P, Lefebvre J, Jois PS, Fan J, Wright MW. New nomenclature for mammalian BSP genes. Biol Reprod. 2009;80(3):394-7.

3. Calvete JJ, Mann K, Schafer W, Sanz L, Reinert M, Nessau S, et al. Amino acid sequence of HSP-1, a major protein of stallion seminal plasma: effect of glycosylation on its heparin- and gelatin-binding capabilities. Biochem J. 1995;310:615-22.

4. Calvete JJ, Raida M, Gentzel M, Urbanke C, Sanz L, Topfer-Petersen E. Isolation and characterization of heparin- and phosphorylcholine-binding proteins of boar and stallion seminal plasma. Primary structure of porcine pB1. FEBS Lett. 1997;407(2):201-6.

5. Menard M, Nauc V, Lazure C, Vaillancourt D, Manjunath P. Novel purification method for mammalian seminal plasma phospholipid-binding proteins reveals the presence of a novel member of this family of protein in stallion seminal fluid. Mol Reprod Dev. 2003;66(4):349-57.

6. Villemure M, Lazure C, Manjunath P. Isolation and characterization of gelatin-binding proteins from goat seminal plasma. Reprod Biol Endocrinol. 2003;1(1):39.

7. Boisvert M, Bergeron A, Lazure C, Manjunath P. Isolation and characterization of gelatin-binding bison seminal vesicle secretory proteins. Biol Reprod. 2004;70(3):656-61.

8. Bergeron A, Villemure $M$, Lazure C, Manjunath P. Isolation and characterization of the major proteins of ram seminal plasma. Mol Reprod Dev. 2005;71(4):461-70.

9. Harshan HM, Sankar S, Singh LP, Singh MK, Sudharani S, Ansari MR, et al. Identification of PDC-109-like protein(s) in buffalo seminal plasma. Anim Reprod Sci. 2009;115(1-4):306-11. doi:10.1016/j.anireprosci.2008.11.007.

10. Fan J, Lefebvre J, Manjunath P. Bovine seminal plasma proteins and their relatives: a new expanding superfamily in mammals. Gene. 2006;375:63-74.

11. Nixon B, Jones RC, Holland MK. Molecular and functional characterization of the rabbit epididymal secretory protein 52, REP52. Biol Reprod. 2008;78(5):910-20. doi:10.1095/biolreprod.107.065524.

12. Plante G, Therien I, Manjunath P. Characterization of recombinant murine binder of sperm protein homolog 1 and its role in capacitation. Biol Reprod. 2012;87(1):20. doi:10.1095/biolreprod.111.096644. 1-11.

13. Plante $G$, Therien I, Lachance C, Leclerc P, Fan J, Manjunath P. Implication of the human Binder of SPerm Homolog 1 (BSPH1) protein in capacitation. Mol Hum Reprod. 2014;20(5):409-21. doi:10.1093/molehr/gau006.

14. Lefebvre J, Fan J, Chevalier S, Sullivan R, Carmona E, Manjunath P. Genomic structure and tissue-specific expression of human and mouse genes encoding homologues of the major bovine seminal plasma proteins. Mol Hum Reprod. 2007;13(1):45-53.

15. Manjunath $P$, Sairam MR, Uma J. Purification of four gelatin-binding proteins from bovine seminal plasma by affinity chromatography. Biosci Rep. 1987;7(3):231-8.

16. Manjunath $P$, Sairam MR. Purification and biochemical characterization of three major acidic proteins (BSP-A1, BSP-A2 and BSP-A3) from bovine seminal plasma. Biochem J. 1987;241:685-92.

17. Desnoyers $L$, Manjunath P. Major proteins of bovine seminal plasma exhibit novel interactions with phospholipid. J Biol Chem. 1992;267(14):10149-55.

18. Muller P, Erlemann KR, Muller K, Calvete JJ, Topfer-Petersen E, Marienfeld K, et al. Biophysical characterization of the interaction of bovine seminal plasma protein PDC-109 with phospholipid vesicles. European Biophys J. 1998;27(1):33-41.

19. Ramakrishnan M, Anbazhagan V, Pratap TV, Marsh D, Swamy MJ. Membrane insertion and lipid-protein interactions of bovine seminal plasma protein PDC-109 investigated by spin-label electron spin resonance spectroscopy. Biophys J. 2001;81(4):2215-25

20. Wah DA, Fernandez-Tornero C, Sanz L, Romero A, Calvete JJ. Sperm coating mechanism from the 1.8 A crystal structure of PDC-109-phosphorylcholine complex. Structure (Camb). 2002;10(4):505-14.

21. Therrien A, Manjunath $P$, Lafleur M. Chemical and physical requirements for lipid extraction by bovine binder of sperm BSP1. Biochim Biophys Acta. 2013;1828(2):543-51. doi:10.1016/j.bbamem.2012.08.020.

22. Greube A, Muller K, Topfer-Petersen E, Herrmann A, Muller P. Influence of the bovine seminal plasma protein PDC-109 on the physical state of membranes. Biochemistry. 2001;40(28):8326-34.

23. Therien I, Moreau R, Manjunath P. Major proteins of bovine seminal plasma and high-density lipoprotein induce cholesterol efflux from epididymal sperm. Biol Reprod. 1998;59(4):768-76.

24. Therien I, Moreau R, Manjunath P. Bovine seminal plasma phospholipidbinding proteins stimulate phospholipid efflux from epididymal sperm. Biol Reprod. 1999;61(3):590-8. 
25. Thérien I, Soubeyrand S, Manjunath P. Major proteins of bovine seminal plasma modulate sperm capacitation by high-density lipoprotein. Biol Reprod. 1997;57(5):1080-8.

26. Thérien I, Bleau G, Manjunath P. Phosphatidylcholine-binding proteins of bovine seminal plasma modulate capacitation of spermatozoa by heparin. Biol Reprod. 1995;52:1372-9.

27. Chandonnet L, Roberts KD, Chapdelaine A, Manjunath P. Identification of heparin-binding proteins in bovine seminal plasma. Mol Reprod Dev. 1990;26(4):313-8.

28. Therien I, Bergeron A, Bousquet D, Manjunath P. Isolation and characterization of glycosaminoglycans from bovine follicular fluid and their effect on sperm capacitation. Mol Reprod Dev. 2005;71:97-106.

29. Manjunath P, Marcel YL, Uma J, Seidah NG, Chretien M, Chapdelaine A. Apolipoprotein A-I binds to a family of bovine seminal plasma proteins. J Biol Chem. 1989;264(28):16853-7.

30. Manjunath $P$, Nauc $V$, Bergeron A, Menard M. Major proteins of bovine seminal plasma bind to the low-density lipoprotein fraction of hen's egg yolk. Biol Reprod. 2002;67(4):1250-8

31. Lusignan MF, Bergeron $A$, Lafleur $M$, Manjunath $P$. The major proteins of bovine seminal plasma interact with caseins and whey proteins of milk extender. Biol Reprod. 2011;85:457-64. doi:10.1095/biolreprod.110.089961.

32. Gwathmey TM, Ignotz GG, Suarez SS. PDC-109 (BSP-A1/A2) promotes bull sperm binding to oviductal epithelium in vitro and may be involved in forming the oviductal sperm reservoir. Biol Reprod. 2003;69(3):809-15.

33. Gwathmey TM, Ignotz GG, Mueller JL, Manjunath P, Suarez SS. Bovine Seminal Plasma Proteins PDC-109, BSP-A3, and BSP-30-kDa Share Functional Roles in Storing Sperm in the Oviduct. Biol Reprod. 2006;74(4):501-7.

34. Sankhala RS, Swamy MJ. The major protein of bovine seminal plasma, PDC-109, is a molecular chaperone. Biochemistry. 2010;49(18):3908-18 doi:10.1021/bi100051d.

35. Nauc $V$, Manjunath P. Radioimmunoassays for bull seminal plasma proteins (BSP-A1/-A2, BSP-A3, and BSP-30-Kilodaltons), and their quantification in seminal plasma and sperm. Biol Reprod. 2000;63(4):1058-66.

36. Jois PS, Manjunath P. The N-terminal part of Binder of SPerm 5 (BSP5) which promotes sperm capacitation in bovine species is intrinsically disordered. Biochem Biophys Res Commun. 2010;394(4):1036-41. doi:10.1016/j.bbrc.2010.03.118

37. Markwell MA, Haas SM, Bieber LL, Tolbert NE. A modification of the Lowry procedure to simplify protein determination in membrane and lipoprotein samples. Anal Biochem. 1978;87(1):206-10.

38. Parrish JJ, Susko-Parrish J, Winer MA, First NL. Capacitation of bovine sperm by heparin. Biol Reprod. 1988;38(5):1171-80.

39. Lenz RW, Ax RL, Grimek HJ, First NL. Proteoglycan from bovine follicular fluid enhances an acrosome reaction in bovine spermatozoa. Biochem Biophys Res Commun. 1982;106(4):1092-8.

40. Dott HM, Foster GC. A technique for studying the morphology of mammalian spermatozoa which are eosinophilic in a differential 'life-dead' stain. J Reprod Fertil. 1972;29(3):443-5.

41. Manjunath $P$, Chandonnet $L$, Leblond $E$, Desnoyers L. Major proteins of bovine seminal vesicles bind to spermatozoa. Biol Reprod. 1994;50(1):27-37.

42. Cardin AD, Weintraub HJ. Molecular modeling of protein-glycosaminoglycan interactions. Arteriosclerosis. 1989;9(1):21-32.

43. Calvete JJ, Reinert M, Sanz L, Topfer-Petersen E. Effect of glycosylation on the heparin-binding capability of boar and stallion seminal plasma proteins. J Chromatogr A. 1995;711(1):167-73.

44. Moreau R, Therien I, Lazure C, Manjunath P. Type II domains of BSP-A1/-A2 proteins: binding properties, lipid efflux, and sperm capacitation potential. Biochem Biophys Res Commun. 1998;246(1):148-54.

45. Tordai $H$, Patthy $L$. The gelatin-binding site of the second type-II domain of gelatinase A/MMP-2. Eur J Biochem. 1999;259(1-2):513-8.

46. Desnoyers L, Manjunath P. Interaction of a novel class of phospholipidbinding proteins of bovine seminal fluid with different affinity matrices. Arch Biochem Biophys. 1993;305(2):341-9.

47. Hung PH, Suarez SS. Alterations to the bull sperm surface proteins that bind sperm to oviductal epithelium. Biol Reprod. 2012;87(4):88. doi:10.1095/biolreprod.112.099721.

48. Bansal P, Chakrabarti K, Gupta SK. Functional activity of human ZP3 primary sperm receptor resides toward its C-terminus. Biol Reprod. 2009;81(1):7-15. doi:10.1095/biolreprod.108.074716
49. Wang M, Lv Z, Shi J, Hu Y, Xu C. Immunocontraceptive potential of the Ig-like domain of Izumo. Mol Reprod Dev. 2009;76(8):794-801. doi:10.1002/mrd.21027

50. Inoue N, Ikawa M, Okabe M. Putative sperm fusion protein IZUMO and the role of N-glycosylation. Biochem Biophys Res Commun. 2008;377(3):910-4 doi:10.1016/j.bbrc.2008.10.073

\section{Submit your next manuscript to BioMed Central and take full advantage of:}

- Convenient online submission

- Thorough peer review

- No space constraints or color figure charges

- Immediate publication on acceptance

- Inclusion in PubMed, CAS, Scopus and Google Scholar

- Research which is freely available for redistribution 